\title{
Including children's perceptions from meditation in a discussion about reflective practices in education
}

\author{
Sue Erica Smith \\ Charles Darwin University, Australia \\ sue.smith@cdu.edu.au
}

Keywords: meditation, mindfulness, Buddhist, education, Asia, narrative, wellbeing, reflection

\begin{abstract}
This paper is a co-constructed narrative comprising of inputs from children and their teachers and contextualisation from the embedded position of the chief investigator in this study to gain insights into how a group of class of Year 5-6 primary school students experienced meditation. The study is situated in a Buddhist Religious Instruction class, where learning was conducted inside a designated weekly half hour session. In accordance with the cultivation of individual responsibility and executive function that is the ethos of Buddhist pedagogy participating students and their volunteer teacher were invited into the research as research inquirers. Again the tradition exhorts the role of an experienced teacher to guide what can become an intrapersonal learning journey through meditation. At a time where mindfulness exercises and permutations have captured the public imaginary, and where educators are showing increasing interest, the discussion is timely. While the study is directed towards secular and plural educational applications, reference to the tradition that has borne mindfulness alerts the field to some considerations as to how the uptake of mindfulness in schools might be applied with further rigour and integrity. Further, the utilisation of children's drawings of happiness scales and their added narratives offers a way in which research into the interior experiences of children might be conducted. Their insights from experience in meditation supports findings from clinical studies with children, and poses a viable addition to current reflective, wellbeing and resilience strategies in education.
\end{abstract}

\section{Introduction}

A shaken bottle of muddy water begins the session. Sitting, backs straight, observing breath, the water settles. Thoughts settle. Water becomes clear... learning the nature of mind. (Cl's classroom observation)

Mindfulness exercises and meditations pose a new addition to the reflective practices that have become orthodox in contemporary teaching, learning and research (Dewey, 1933; Schön, 1983; Marchel, 2004; Moon, 2005; Sherwood et al.) Reflection in education currently includes reflective writing in journals, blogs and wikis, video and audio recording, critical incident discussions to consider helpful or unhelpful behaviours, drawing, concept maps, role plays, drama, storytelling, music and, with increasing interest, yoga, mindfulness and meditation. All of these employ metacognitive strategies where past experiences are reviewed and decisions 
and future actions are determined (Donovan et al., 1999). The cognitive capacity to analyse and attempt to understand problems, often through active exploration of experiences can be used to gain new or greater understanding. Reflection is awareness and understanding of thought. Crucially though, present awareness is more than often subsumed in these metacognitive and reflective practices, yet seldom is specifically taught. Meditation, mindfulness and yoga exercises address this gap. The weekly half hour Religious Instruction (R.I.) classes drawn upon here provided an opportunity to explore some perceived effects of present-awareness exercises from children's perceptions of their meditation experiences.

\section{Background}

Meditation has garnered a steady stream of interest for use in classrooms for some time (Crook, 1988; Erriker, \& Erricker, 2001; Fontana \& Slack, 2002; Rozman, 2002; Hawkes, 2003) and is now being incorporated into Social and Emotional Learning strategies (Lantieri, 2008). Targeted research into mindfulness practices with youth is also producing compelling results where they have been included into therapies to treat children with attention-deficit hyperactivity disorders (Harrison et al., 2004; Jensen \& Kenny, 2004; Zylowska et al., 2007), stress (Wall, 2005), and anxiety (Semple et al,2005), aggression (Singh et al., 2007) and improved attention (Peck et al., 2005; Rani \& Rao, 2000). Neurobiological research has also shown that stress inhibits learning (Introini-Collision et al., 1991; Christianson, 1992) and, in the first instance as seen below, the calmness induced through meditation stands to be a proactive measure to address these learning inhibitions.

Brain research with proficient long-term Buddhist meditators has also alerted the field to some of what these practices can achieve. Brain structure can be changed to sustain kindly and happy dispositions through compassion meditations (Lutz et al., 2004; Ricard, 2006), while some compassion meditation promoted some, but lesser changes, and wellbeing (Urry, et al., 2004). Another study (Carter et al., 2005) revealed how long-term Buddhist meditators could concentrate and change focus with exceptional proficiency. Concentration, calm, kindness, emotional regulation and wellbeing outcomes from meditation are deserving of close attention by educators.

Mindfulness has become common-speak for meditation, but attention to the roots and etymology of the practices provides the field with rigour, nuance and scope that might otherwise be precluded. A discourse on mindfulness was first taught by the Buddha, as documented in the Sattipattana Sutta: Frames of Reference (2010). It is an essentially Buddhist meditation (Rahula, 1978, p. 69), and indeed Buddhist practice in all of its authentic representations is about the cultivation of mindfulness. The R.I. program drew on this tradition: mindfulness of breathing (annapanasati: Pali), that develops concentration for calm abiding (samatha: Pali), insight that leads to emotional regulation and ethics (vipassana: Pali) and kindness, love and compassion to selves and others (metta: Pali). Etymologically 'meditation' the same Latin route as 'medicine' (from Sanskrit: madh) meaning to be wise, heal, cure. Children were taught these types of meditations with age-appropriate adaptations. For example, calm abiding by watching the muddy water settle, and kindness was extended to pets, friends and family and then towards others. In the Buddhist tradition developing loving-kindness is integral. Firstly because mind is conceived as both cognitive and affective, and secondly, that a loving mind loses space for anger, hatred and harm. It is essential for resilience: kindness to oneself, ethical conduct, respect and kindness to others. 


\section{Context}

These R.I. classes were offered through the Buddhist Council of Victoria. Immigrant families from many Asian countries had requested that a Buddhist program be offered, and a curriculum was devised that included meditation and Buddhist stories (Smith \& Seah, 2008). It aimed to be non-sectarian, include all children and support current education practices. Across all the schools in the program, half of the participating children were from non-Buddhist families. Of the 22 Year 5-6 students in this study only two were from Buddhist families. Apart from another two students, they had all been in Buddhist classes before, half of whom had attended for the past three years. They had practiced aiming for the formal sitting posture and meditating. In their evaluations from previous years they reported that they had fun with the ethical stories, discussions and creative activities that were devised to bridge introspective reflection and purposeful activity in their lives. Helen, their volunteer teacher, was an experienced meditator and a professional teacher. My experience was similar, and I joined the program as its coordinator and as a researcher.

\section{Methods}

In a scant half hour per week my research methods needed to abide by the ethos of the program, and not divert student learning and volunteer teacher time, to my research agenda.

After ethics clearance and permission from the school, teachers and students were recruited into the study as research inquirers. I emulated Patti Lather's stance that "involves the researched in a democratized process of inquiry characterised by negotiation, reciprocity, empowerment - research as praxis" (Lather, 1986, p. 257). This approach equally honoured Buddhist intentions. I sought that the students' participation in both the research as well as the program would enrich their learning experiences, and that they too could shape the development of the program. However, I did not aim for participants in the study to move to politically empowered positions, as is generally perceived in the emancipatory research that Lather would suggest, although 'awakening mind' in Buddhism is synonymous with liberation. Liberation in this instance is focused on freedom and dexterity of thought.

\section{The Happiness Scale}

Inspired by research with children using drawings (Di Leo,1973; Kosslyn et al.,1977; Gardner, 1980; Anning \& Ring, 2004) I devised a happiness scale, as both a research and a heuristic tool, to provide records of each student's subjective experiences. I was skeptical that interview and questionnaire data alone would give as accurate a picture, for I could foresee that in interview students may say what they thought I would like to hear and a questionnaire would rely upon language with which I could not assume the children were familiar. I was impressed by Cummins and Lau (2004) who had produced a Personal Well-being Index for School Children (PWI-SC). They had grappled with semantic distinctions and eventually interchanged 'happiness' for 'wellbeing' because children would use 'happiness' as an equivalent descriptor of their general wellbeing (Cummins \& Lau, 2004, p. 5). It was a suitably understood term from which children could assess their experiences as research inquirers.

Although I was not seeking a psychometric test, that Cummins and Lau's use of happiness to generate wellbeing data from child populations and their Likert scale approach paralleled my agenda. Helen and I did not want children to be pressured to achieve a perceived optimal standard, but rather learn to observe their minds, and so a prescriptive, ordinal scale would have been inappropriate. Students would draw their own scales with three points: a sad, neutral and happy face. We wanted the children to engage in their own assessments and maintain their agency. 
Students in the study drew a Happiness Scale before each meditation session and placed themselves both before $(B)$ and after $(A)$ the session, and had the option to write comments. This tool brought a creative, visual element to the metacognitive task of reflecting about their dispositions. Initially, drawing the scale and checking wellbeing would facilitate the meditative skill of observing the mind. It was a tool to help children observe thoughts and feelings, and the changeable nature of thoughts and feelings that remained consistent with Buddhist practice. The implementation of a scale removed dependence upon language ability to articulate their perceptions, and was thereby accessible to all of the children. It was also a springboard for children to identify and name thoughts and feelings if they wanted to and have their privacy respected. Students became researchers of their own happiness.

In addition to being an aid to student learning, the scale was also used as a self-report research instrument to collect data. It also served as means for discreet communications between the teacher and students. Guidance from a teacher is also part of the pedagogy of the tradition and it would have been inappropriate to have excluded teacher involvement in this context.

Over a 22 week period these students drew a scale in their books in whichever way they chose and recorded their personal pre- and post-meditation assessments. Meditations lasted from four to seven minutes. Even though this group of ten to twelve year-olds had some experience, the cultivation of some discipline in the exercises did not over-rule the teacher being pragmatic and shortening the sessions some days. Sometimes the teacher would have a brief discussion after the meditation, but not always.

Use of the Happiness Scale became routine for the class over the period and it appeared that the exercise made meditation sessions more purposeful for the students. The agency afforded by students drawing their scales allowed them to rate their base-line happiness where they chose. Some students would place feeling good midway on the scale, some lower, others at consistently high levels.

\section{Narratives from the Happiness Scale entries}

From the twenty-two sessions that were delivered that year I aggregated each child's shifts on their Happiness Scales to look for patterns and emergent themes. In this class of twenty-two, seven students recorded positive change in every entry and another five recorded happier change after $90 \%$ of sessions. Half the class charted over the year recorded that they felt consistently happier and more positive for having meditated. Sometimes children would not place themselves higher on the scale after meditation, but would comment that they felt more calm, clear or relaxed. These I took to be positive outcomes from the meditation, and for this reason I bracketed zero movement on the scale with positive responses.

However, quantified changes alone could not capture the nuances of experiences. For example, Jenna rated her change on the scale as happier $50 \%$ of the time, yet the quantification belied her engagement with the exercises. She had chosen to attend the Buddhist classes for several years and had remained an interested and participatory student. Her mother, whom I interviewed, believed that Jenna enjoyed and valued the classes, and had been meditating to calm herself before sports events and as a technique to calm and focus herself in other situations when she was getting keyed up. Jenna found usefulness in her meditation practice. (Remember too, that 'happiness' was introduced for children to check their thoughts and feelings. It was not presented as an expected outcome.)

Tee, whose aggregate was $67 \%$ over the year, was another bright, engaged student who had also been with the classes since their inception. Her workbook comments shown later in 
Figure 2 and discussed below indicated that she valued the classes, "THANKS." Other times she might have been trying too hard to benchmark achievements and even became hyperaware, noticing every external noise and itch. In these instances the records were invaluable vehicle for the teacher to offer gentle guidance.

The book entry below is indicative of the personalised entries typical of any of the sessions and the spectrum of comments recorded. We see the child's excitement about a photo, noticing feeling calmer, "carmer" (sic), and even sleepy. The teacher's comments to the side show the steady presence she maintained with her students. This way, over the course of the year students produced narratives of their experiences.

Figure 1: Feelings about the day and meditation
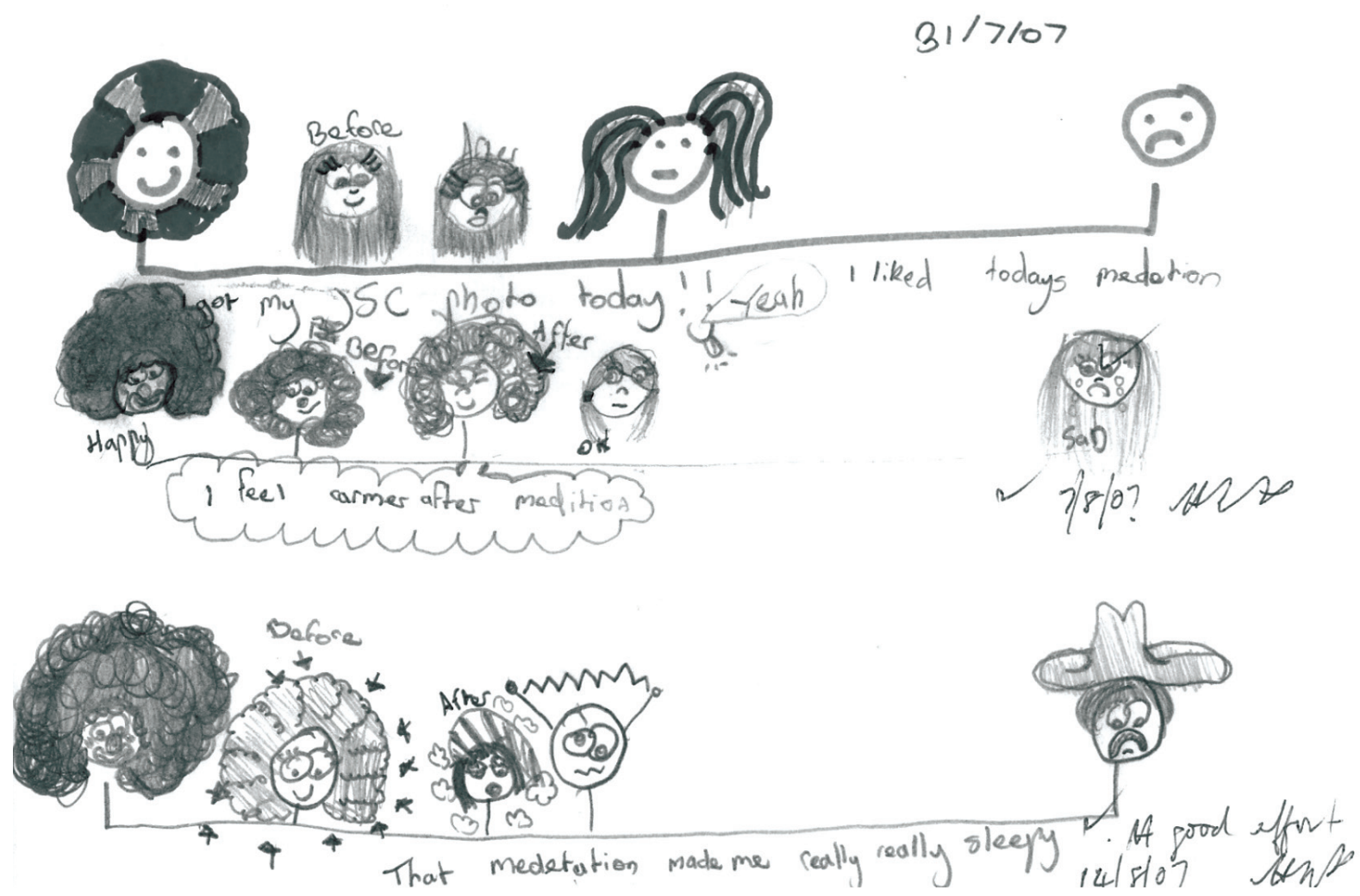

\section{Focus/ concentration}

Children worked to focus their attention and with experience, they linked feeling calm with the ability to concentrate. Wayne approached the sessions with earnestness. Marking consistently happier shifts on his scales he wrote, "I wasn't focused at the start but then I got focused," and before, "I feel pretty good," and after, "I felt really good through meditation because I was focused." The teacher wrote, "Well done." She knew that it takes effort - and some days just too much effort. Wayne wrote with excited anticipation, "I'm happy because it's my friend's Birthday" and then, "I wasn't that focused in med[itation]. But I'm still happy." The effort over the weeks however seemed worthwhile. Before, "I feel the best," and after, "I feel happy and calm because I was focused in meditation."

Even non-compliance created awareness. One occasion Harry wrote, "I was very happy and feeling good but during meditation I don't think I concentrated hard enough to improve." 


\section{Calm insights}

Even though through initially practising mindfulness of breath as a concentration exercise, children noticing that they were more calm after meditation was the most consistent theme. Tess wrote before, "I feel OK" and afterwards, "More calm. See stuff in a different light." Rosie showed some subtle analysis that she sustained throughout the year. One day before meditation she wrote, "I felt relaxed but not tired, which is good. Assembly was pretty good and that's not a bad start to the day," and afterwards, "I felt more alert. I'm not sure if that's good or not." The teacher assured, "very good." Another day, before she wrote, "I felt happy and peaceful," and after, "I felt slightly more tired but definitely very calm." Engagement with subtleties continued, "I slept fairly well, so I am not very tired, which helps," while afterwards, "I didn't feel very different but a bit better." Another day she wrote, "I felt bright and cheerful and wasn't tired," and then, "I was more calm and peaceful but still bright."

Teaching techniques for relaxation provide balance to achievement orientated education and arguably have a valid place in a curriculum. The students in this study appreciated the opportunity to relax in the weekly sessions. Similar data indicating consistent positive shifts in student perceptions of their happiness may well be generated from relaxation exercises alone, I do not know. In terms of this program relaxation was valuable, although a side benefit alongside the more rigorous task of cultivating awareness. We were more interested in exploring whether the children were learning skills that would bring them closer to self-knowledge and ways to enhance their wellbeing and more considered decision making.

When body and mind are integrated to feel calm and peaceful, and given validation through the teacher's guidance, it can be seen from the children's comments that they became aware of many sensations and cognitions that they described under the rubric of Happiness.

Shyla took her role as a research inquirer into her homelife and communicated (to her teacher) in her after comment, "Now I'm relaxed. On the weekend I did some meditation and I found it really effective just to concentrate on my breath and not tell myself to do anything."

\section{Emotional regulation}

Differences between relaxation and meditation become more apparent when we see evidence of students' emotional regulation that is facilitated through the space provided in present awareness. Without conscious awareness of what the mind is thinking and feeling, in Buddhist reasoning, it is more difficult to develop control over cognitive and affective functions, foresee alternatives and consequences, and act in ways that are respectful and beneficial to selves and others. Although it required effort, the students in this study appreciated letting their turbulence settle and glimpse a clearer quality in their minds. One morning Rita wrote beforehand, "HYPER feel like talking," and afterwards, "no better but not hyper." Having arrived with low expectations one morning Ronny wrote, "not good grumpy, tired and I don't like Tuesday," and then afterwards with a hint of amazement, "but I feel much better, I feel enlightened by meditation."

\section{Wellbeing and resilience}

This meditative approach to reflection is a mind and body exercise. Neither is negated or prioritised. The yoga traditions such as Buddhism emphasise attention to physical posture to provide a stable platform from which to develop the art of calm and balanced attention. Attention to the body, stretching and doing frog, dog and tree yoga-like exercises in preparation to sitting was routine in these classes. From spaces of calm and balanced attention some 
children were able to shift the focus of their attention where, on occasions, allowed them to feel better when coping with pain and sickness. Some comments included, "I'm pretty cold and this morning, I felt a bit sick" and moved to "I feel calmer and my heart feels warm." Another student wrote, "I feel annoyed because my hip has been sore for a week," although afterwards, "I feel a bit better but my hip is still sore." Another child wrote weakly, "I feel OK but I have a cold," yet afterwards, "I don't feel bad anymore."

Children also revealed how the meditations provided new ways to reflect on their anxieties and adopt more resilient attitudes. Tee was sad because her mother was in Singapore but discovered that she was able to feel better. Her graphics below in Figure 2 are punctuated with delight and gratitude. Before meditation Rosie wrote, "I'm kind of nervous about Maths Olympiad," and then afterwards, "I felt less tense and more relaxed." After a session Jenna wrote, "I feel better about not having food for lit[erature] group because I know it is not the end of the world."

Figure 2: Tee finds meditation helpful when feeling sad

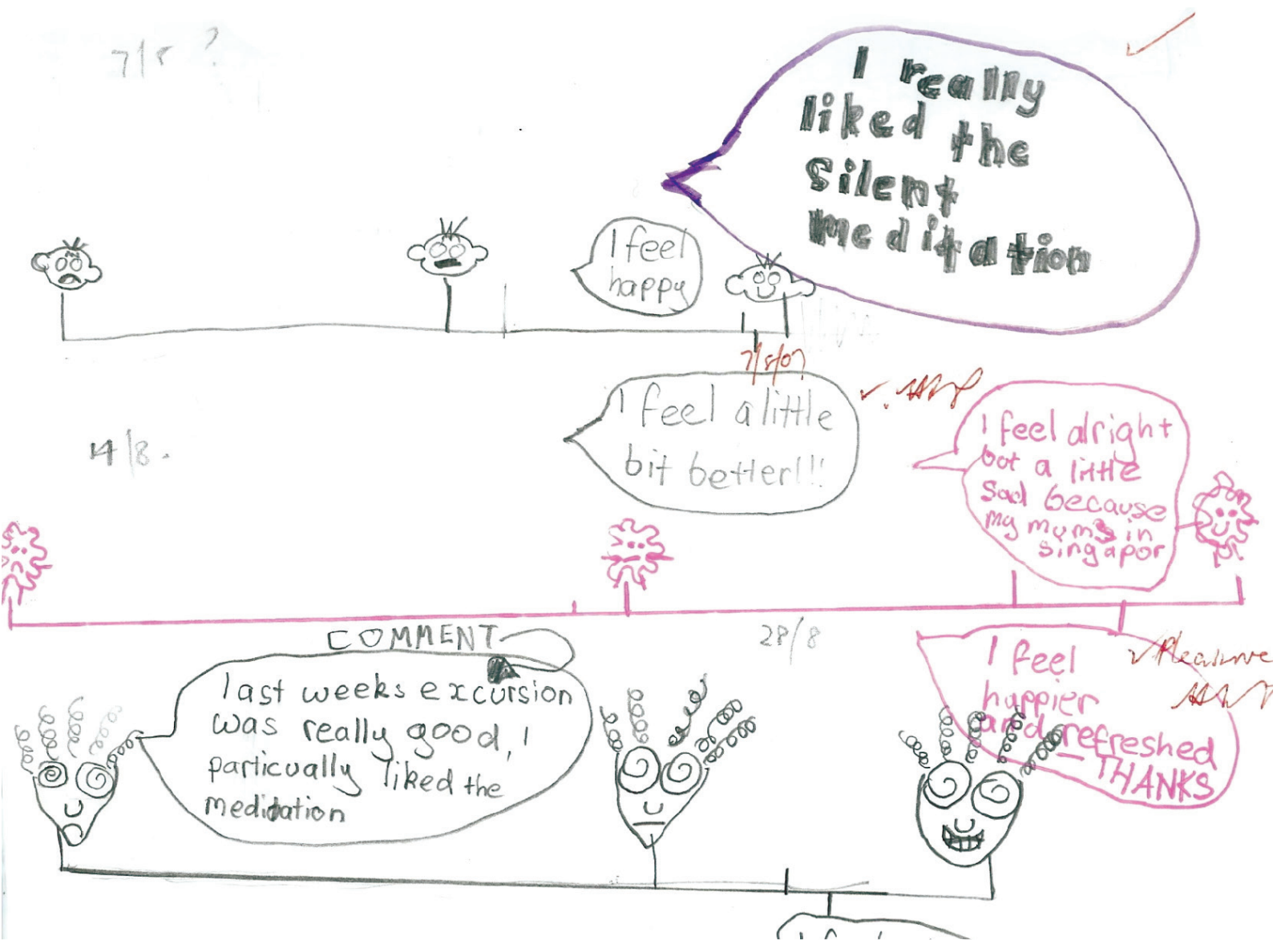

Some children however were very unhappy and with difficulties at the forefront of their minds, movement to stillness was resisted. For these students engagement by the teacher had further importance. May wrote candidly, "that's me. I haven't felt happy for a while," and after, "still." Helen wrote, "It will take patience, kindness, for you, for yourself." In another entry May began, "I feel full of regret! Again I don't know why," yet afterwards, "I am happy because I have accomplished something, I don't know what though." Helen replied, "(feeling happy) Very cool. Well done. You did that!" She also alerted the classroom teacher to these entries. 
May had already been referred to the pupil welfare coordinator. However, May persevered throughout the term and her scale entries went up and down. Towards the end of the year she wrote, "I am happy but something is weighing me down," and after, "I feel RELAXED I think meditation helps calm my mind a whole lot." "Yes."

Figure 3: honest attention

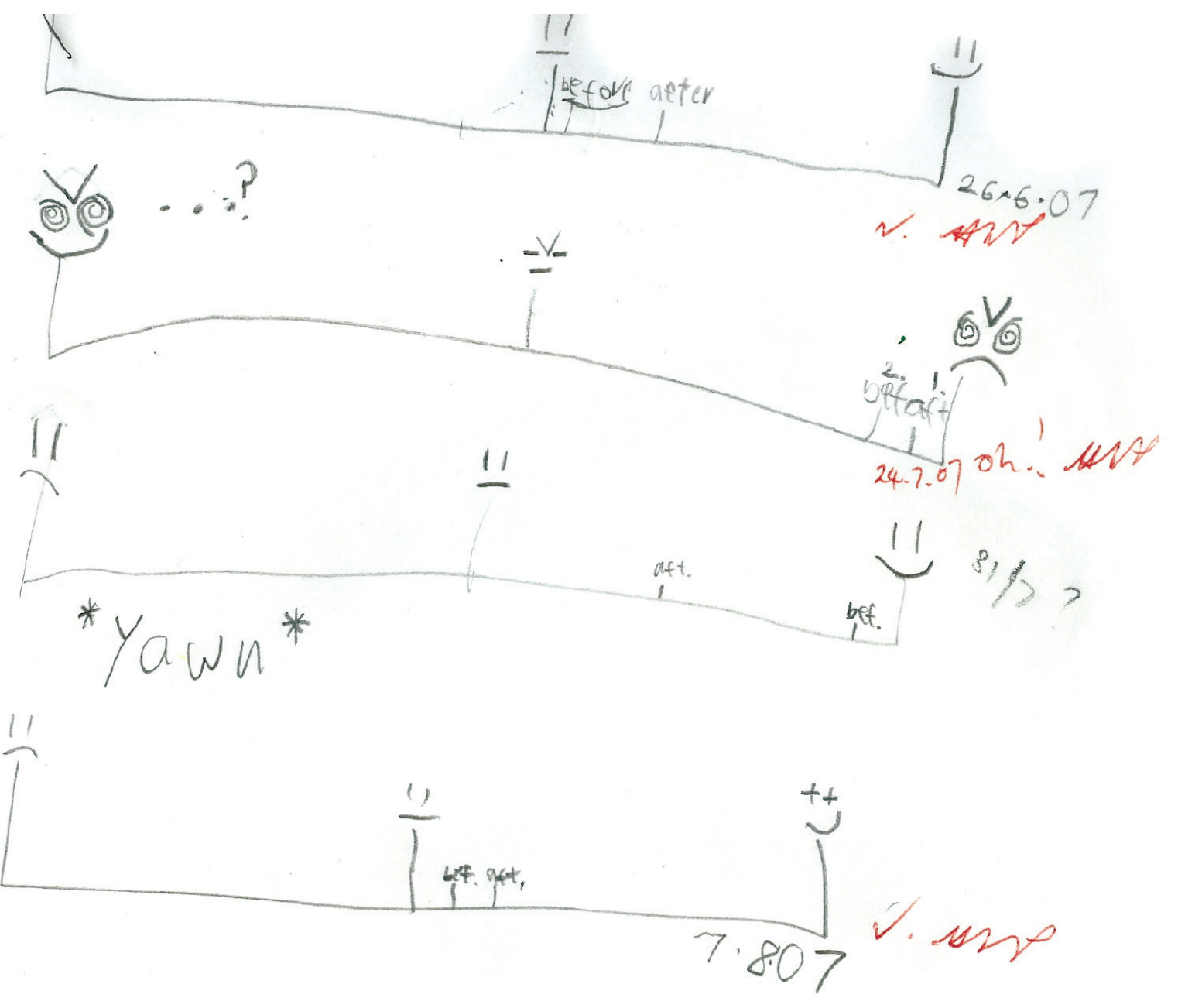

The entry above Figure 3 is from a rowdy boy. The observing teacher confided that he had significant issues at home and had trouble concentrating in all of his classes. In the second entry in Figure 3 he appeared not to have much inclination for happiness, given the grim looking scale, and, having started from a low base felt worse. From the ambiguity of the next entry he may not have felt much better, whereas on other occasions his appraisal was better. As cited earlier in this paper, individual mindfulness sessions incorporated into other clinical therapies might be more effective than was apparent in the class activity. Increasingly teachers have children with these types of behaviours in their classrooms and the rowdy and troubled students can test a teacher's resolve to persevere with mindfulness sessions. Classroom misbehaviour and potential distress from children trying too hard, or being confronted by overwhelming thoughts and feelings can be mitigated by a teacher who is familiar with the vagaries and sometimes confrontational propensities that can arise when the mind is directed to look at itself. Silence alone can be confronting. However when sessions were kept short and responsive to the children's various dispositions, we found here that these children developed their capacity to develop mindful awareness even when session times were 2 or 3 minutes duration on occasion. Happiness is not the end-point but rather the point is the practise. 
This illustration above provides some reason for the meditation tradition to recommend an experienced meditation practitioner be the teacher, and that's/he be supported by [professional] colleagues. This type of professionalism holds true for all aspects of teaching i.e. that the teacher holds content knowledge and draw upon pedagogical skills that are supported by professionals in the field. Mindfulness or meditation in schools needs not languor with lesser standards. Students can benefit.

As the observing classroom teacher wrote, "The reflections on the happiness scale are powerful, and treated seriously." She also noticed perceptual shifts and some implications from these:

They are becoming far better at tuning out distractions; greater self-discipline. Students always approach these sessions with such a positive mind-set. Selfreflection is a large element, and has huge implications across all aspects of life. The free flowing of ideas is totally engaging!!

\section{Conclusion}

The narrative constructed here from students' journal entries using happiness scales, engagement with education colleagues, mindfulness literature and secular engagement with the Buddhist meditative tradition provides good pause to expand the framing and applications of reflection in current pedagogy. While mindfulness practices have now become familiar to many persons in western societies, and are increasingly drawing interest from educators, the discussion here provides a timely reminder to the field that lessons learnt from over 2,500 years (and many millions of practitioners) can inform secular education of the potentialities and scope that mindfulness and meditation can provide. Importantly this narrative relies upon the participating children's records of their individual perceptions of themselves both before and after twenty-two weekly meditation sessions. Their responses show how their learning to cultivate present awareness has played a dynamic role in their thinking processes they noticed that they could become calm. Their minds possessed clear-water clarity when thoughts settled. With familiarity reflecting in this way they also realised that they could direct their attention elsewhere. Anxieties could be less fixated, physical ailments less dominant. They could cope better and feel better. The participating students became active research inquirers into the nature of their minds and learnt strategies to further become their own agents of change. This study illustrates some of the tremendous potential for meditation and mindfulness to be integrated into existing learning, and wellbeing and resilience strategies in particular.

\section{References}

Anning, A., \& Ring, K. (2004). Making sense of children's drawings. UK: McGraw-Hill Education.

Carter, O.L., Presti, D.E., Callistemon, C., Ungerer, Y., Liu, G.B., \& Pettigrew, J.D. (2005). Meditation alters perceptual rivalry in Tibetan Buddhist monks. Current Biology, 15(11), 412-413

Crook, R. (1988). Relaxation for children. Katoomba: Second Back Row Press.

Cummins, R.A., \& Lau, A.L.D. (2004). Personal wellbeing index - school children (PWI-SC), 2 nd Edition. School of Psychology, Deakin University.

Davidson, R.J. (2004). Well-being and affective style: neural substrates and biobehavioural correlates. Philosophical Transactions of the Royal Society, 359, 1395-411. 
Dewey, J. (1933). How We Think, New York: D. C. Heath. Classic and highly influential discussion of thinking. In Smith, M.K. (1999). Reflection, :learning and education. Retrieved from Encyclopaedia of Informal Education.

Di Leo, J.H. (1973). Children's drawings as diagnostic aids. New York: Brenner/Mazel.

Donovan, M.S., Bransford, J.D., \& Pellegrino, J.W. (1999). How people learn. Retrieved March, 8, 2006.

Erriker, C., \& Erricker, J. (Eds.) (2001). Meditation in schools: a practical guide to calmer classrooms. London: Continuum.

Fontana, D., \& Slack, I. (2002). Teaching meditation to children. London: Thorsons.

Gardner, H. (1980). Artful scribbles: The significance of children's drawings. New York: Basic Books.

Hawkes, N. (2003). How to inspire and develop positive values in your classroom. Cambridge: LDA.

Introini-Collision, I.B., Miyazaki, B., \& McGaugh, J.L. (1991). Involvement of the amygdala in the memory-enhancing effects of clenbuterol. Psychopharmacology, 4(104), 541-4.

Ivanovski, B,. \& Malhi, G. (2007). The psychological and neurophysiological concomitants of mindfulness forms of meditation. Acta Neuropsychiatrica, 19(2), 76-91, Retrieved from http://www3. interscience.wiley.com/journal/118521718/abstract?CRETRY $=1 \& S R E T R Y=0$.

Kosslyn, S. M., Heldmeyer, K. H., \& Locklear, E. P. (1977). Children's drawings as data about internal representations. Journal of Experimental Child Psychology, 23(2), 191-21

Lantieri, L. (2008), Building emotional intelligence: techniques to cultivate inner strength in children. Boulder, CO: Sounds True.

Lather, P. (1986). Research as praxis. Harvard Educational Review, 56(3), 257-278.

Lutz, A., Greischar, L.L., Rawlings, N.B., Ricard, M. and Davidson, R.J. (2004). Long-term meditators self-induce high-amplitude gamma synchrony during mental practice. Proceedings from the National Academy of Science, 101(46), 16369-16373.

Marchel, C.A. (2004). Evaluating Reflection and Sociocultural Awareness in Service Learning Classes, Teaching of Psychology, 31(2), 120-123.

Moon, J. (2005). Guide for Busy Academics no. 4: Learning through Reflection. York: The Higher Education Academy.

Rahula, W. (1978). What the Buddha taught. London: The Gordon Fraser Gallery Ltd.

Ricard, M. (2006). Happiness: a guide to developing life's most important skill. New York: Little, Brown and Company.

Rozman, D. (2002). Meditating with children: the art of concentration and centering: a workbook on new educational methods using meditation. Buckingham, VA: Integral Yoga Publications.

Ricard, M. (2006). Happiness: a guide to developing life's most important skill. New York: Little, Brown and Company.

Bhikkhu, T. (2010). Satipatthana Sutta: Frames of Reference (MN 10) [translated from the Pali]. Access to Insight (Legacy Edition). Available from http://www.accesstoinsight.org/tipitaka/mn/mn.010.than. html.

Schön, D. (1983). The reflective practitioner. New York: Basic Books.

Semple, R.J., Reid, E.F.G., \& Miller, L. (2005). Treating anxiety with mindfulness: an open trial of mindfulness training for anxious children. Journal of Cognitive Psychotherapy, 19, 379-91. 
Sherwood, G., Freshwater, D., Taylor, B., \& Horton-Deustch, S. (2005). The Scholarship of Reflective Practice. USA: Sigma Theta Tau International Press.

Singh, N.N., Lancioni, G.E., Joy, S.D.S., Winton, A.S.W., Sabaawi, M., Wahler, R.G., \& Singh, J. (2007). Adolescents with conduct disorder can be mindful of their aggressive behavior. Journal of Emotional and Behavioral Disorders, 15(1), 56-63

Smith, S.E., \& Seah, S. (2008). Discovering Buddha: lessons for primary school. Melbourne, Vic: Buddhist Council of Victoria.

Urry, H.L.,Nitschke, J.B., Dolski, I., Jackson, D.C., Dalton, K.M., Mueller, C.J., Rosenkranz, M.A., Ryff, C.D., Singer, B.H., \& Davidson, R.J. (2004). Making a life worth living: neural correlates of wellbeing. Psychological Science, 15(6), 367-72. 